\title{
A visão do contador sob a perspectiva do empreendedorismo nos escritórios de
}

\section{contabilidade}

\author{
The accountant's view from the perspective of entrepreneurship in accounting offices \\ La mirada del contador desde la perspectiva del emprendimiento en las oficinas contables
}

Recebido: 06/07/2021 | Revisado: 15/07/2021 | Aceito: 19/07/2021 | Publicado: 26/07/2021

Elvis Gomes Marques Filho

ORCID: https://orcid.org/0000-0003-2681-6094 Universidade Estadual do Piauí, Brasil

E-mail: elvisfilho@pcs.uespi.br

Mariana Luz de Carvalho

ORCID: https://orcid.org/0000-0002-3213-4690 Universidade Estadual do Piauí, Brasil E-mail: srtamarih_luz@hotmail.com

Maria do Socorro de Sousa Pinheiro

ORCID: https://orcid.org/0000-0001-5303-005X Universidade Estadual do Piauí, Brasil E-mail: srtamarih_luz@hotmail.com

Luciano Silva Figueiredo

ORCID: https://orcid.org/0000-0002-6564-2720 Universidade Estadual do Piauí, Brasil

E-mail: lucianosilva@pcs.uespi.br

Janaína Alvarenga Aragão

ORCID: https://orcid.org/0000-0002-7146-2718 Universidade Estadual do Piauí, Brasil E-mail: janainaalvarenga@pcs.uespi.br

Evandro Alberto de Sousa

ORCID: https://orcid.org/0000-0002-5477-8091 Universidade Estadual do Piauí, Brasil

E-mail: profevandro@uespi.br

Aline Maria Barbosa Lopes

ORCID: https://orcid.org/0000-0002-0536-1249 Universidade Estadual do Piaú, Brasil E-mail: janainaalvarenga@pcs.uespi.br

\begin{abstract}
Resumo
O objetivo central deste artigo consiste em analisar a visão dos contadores que empreendem seu próprio negócio, utilizando o empreendedorismo como uma ferramenta de auxílio no desenvolvimento do trabalho contábil, nos escritórios de contabilidade da cidade de Picos-PI. Dessa forma, os contadores podem ser os indivíduos responsáveis pelo ato de empreender, se detiverem características e habilidades que facilitem o processo de inovação, diante do ambiente de globalização e transformação. Para a realização deste estudo, foi aplicado um questionário aos proprietários de escritórios de contabilidade de Picos-PI. Acerca da metodologia, este estudo se estruturou em três etapas: levantamento bibliográfico, questionário estruturado e análise dos dados quantitativos e qualitativos. No que diz respeito aos resultados, destaca-se que, mediante a apuração e a análise dos dados, o presente estudo revelou que os participantes da pesquisa possuem visão empreendedora, desde o processo de abrir até gerir seu próprio negócio, demonstrando que possuem perfil empreendedor.
\end{abstract}

Palavras-chave: Empreendedor contábil; Mercado de trabalho; Picos.

\begin{abstract}
The main objective of this article is to analyze the vision of accountants who undertake their own business, using entrepreneurship as an aid tool in the development of accounting work, in accounting offices in the city of Picos-PI. In this way, accountants can be the individuals responsible for the act of being an entrepreneur, if they have characteristics and skills that facilitate the innovation process, in the face of an environment of globalization and transformation. To carry out this study, a questionnaire was applied to the owners of accounting offices in Picos-PI. Regarding the methodology, this study was structured in three stages: bibliographic survey, structured questionnaire and analysis of quantitative and qualitative data. With regard to the results, it is highlighted that, through the calculation and analysis of the data, the present study revealed that the research participants have an entrepreneurial vision, from the opening processor to managing their own business, demonstrating that they have an entrepreneurial profile.
\end{abstract}

Keywords: Accounting entrepreneur; Job market; Picos. 


\begin{abstract}
Resumen
El objetivo principal de este artículo es analizar la visión de los contadores que emprenden su propio negocio, utilizando el emprendimiento como herramienta para ayudar en el desarrollo de la labor contable, en las oficinas de contabilidad de la ciudad de Picos-PI. De esta forma, los contables pueden ser los responsables del acto de ser emprendedor, si cuentan con características y habilidades que faciliten el proceso de innovación, ante un entorno de globalización y transformación. Para la realización de este estudio se aplicó un cuestionario a los propietarios de oficinas contables en Picos-PI. En cuanto a la metodología, este estudio se estructuró en tres etapas: levantamiento bibliográfico, cuestionario estructurado y análisis de datos cuantitativos y cualitativos. Con respecto a los resultados, se destaca que, a través del cálculo y análisis de los datos, el presente estudio reveló que los participantes de la investigación tienen una visión emprendedora, desde el procesador de apertura hasta la gestión de su propio negocio, demostrando que tienen un perfil emprendedor.
\end{abstract}

Palabras clave: Emprendedor contable; Mercado de trabajo; Picos.

\title{
1. Introdução
}

O campo de aprendizagem designado como empreendedorismo vem se fortalecendo devido à ampla diversidade que o assunto proporciona. Dentre essa diversidade, destacam-se os seguintes assuntos: a capacidade de inovar; assumir riscos; buscar a independência financeira e a realização pessoal (Cavalcanti et al., 2018). O Empreendedorismo em si volta-se para o processo de desenvolvimento de um negócio, ou um conjunto de atividades no qual esse processo resulta na geração de um novo empreendimento de sucesso. Mediante esse processo, o ato de empreender está ligado à utilização de recursos através de uma forma criativa, a inovação, a capacidade de assumir riscos e a busca de novas oportunidades, ou seja, empreender é despertar a capacidade de criação, por meio do estabelecimento de objetivos, para se alcançar um resultado positivo (Fialho $e t$ al., 2007).

Os empreendedores são considerados os agentes responsáveis pelas mudanças na Economia, estando a serviço de novos mercados ou criando meios para a criação de novos produtos de consumo, como também impulsionando o mercado financeiro. Ou seja, o empreendedorismo encontra-se fortemente associado com a inovação (Schumpeter, 1982). A utilização da contabilidade é algo totalmente indispensável para uma empresa, tanto para as de pequeno porte quanto para as outras. No entanto, percebe-se que muitas empresas de pequeno porte têm entrado em estágio de falência como consequência da não utilização das ferramentas de gestão fornecidas pela contabilidade (Marion, 2009).

Por ser considerada uma das profissões mais antigas, a contabilidade, apesar de possuir uma idade remota em relação a sua origem, não perdeu sua importância e sua necessidade dentro do mercado econômico globalizado. Vale ressaltar ainda que a contabilidade é uma ciência responsável pelo controle de todas as informações, a fim de acompanhar a situação patrimonial da empresa, pois é a partir da análise dos pontos positivos e negativos que podemos estabelecer metas viáveis para garantir o futuro da empresa (Santos et al., 2015).

Sobre a profissão contábil e as oportunidades oferecidas pela mesma pode se afirmar que:

As oportunidades são infinitas. A profissão contábil é atualmente uma das mais valorizadas e disputadas no mercado. O profissional com este perfil está capacitado a ocupar posições no alto escalão de empresas de qualquer ramo de atividade ou mesmo, prestar serviço como um franqueado para eles. Sua visão de negócios, sobre as normas de todos os tipos (instâncias diferentes, municipais, estaduais e federais), de finanças, da economia e do direito fazem este profissional ter a tendência natural de ser um estrategista/consultor e não um mero técnico, que apura números e prepara relatórios (Lúcia, 2012, p. 1).

O profissional contábil capacitado poderá atuar no mercado de trabalho contemporâneo da seguinte maneira: analisando a viabilidade de uma empresa no mercado, oferecendo consultorias trabalhistas, realizando o planejamento de contas, auxiliando em conflitos societários, fazendo previsão de custos, encargos financeiros e tributários. Este profissional precisa estar comprometido com seu trabalho e constantemente capacitando-se e aperfeiçoando-se, para, dessa forma, desenvolver um perfil empreendedor (Andrade, 2012). 
Diante dessas concepções, pretendeu-se indagar: o que o empreendedorismo pôde trazer de relevante para os escritórios de contabilidade e como isso poderá influenciar a carreira contábil no futuro? Como justificativa para a realização deste estudo, apontou-se a compreensão sobre o desenvolvimento do empreendedorismo contábil nos escritórios de contabilidade do município de Picos, no Estado do Piaú, e como isso pôde influenciar de maneira significativa ou não no processo de desenvolvimento da carreira contábil para o futuro da classe, mostrando novas formas de inovação dentro do mercado de trabalho, através da exploração de novos conhecimentos e visualização de novas oportunidades de negócios.

No que se refere ao objetivo central desta pesquisa científica, apresentou-se a análise da visão dos contadores que almejam empreender seu próprio negócio, utilizando o empreendedorismo como uma ferramenta de auxílio nesse processo de evolução do empreendedorismo contábil, dentro dos escritórios de contabilidade da cidade de Picos-PI. Já em relação à estrutura, esta pesquisa cientifica desenvolveu-se através de uma revisão de literatura, cuja divisão em subtítulos teve como finalidade destacar os seguintes objetivos específicos: definir o empreendedorismo a partir do seu conceito, estabelecendo uma relação entre empreendedorismo e contabilidade; identificar o perfil profissional do contador no município de Picos-PI, sob a perspectiva do empreendedorismo nos escritórios de contabilidade; discutir como o empreendedorismo pôde ajudar na valorização da profissão contábil no município de Picos-PI.

\section{Metodologia}

Quanto à área demográfica escolhida, esta pesquisa foi realizada nos escritórios de contabilidade da cidade de Picos, no Estado do Piaú. Como instrumento de coleta de dados foi enviado um questionário estruturado e fechado, via e-mail, juntamente com o Termo de Consentimento Livre e Esclarecido (TCLE), para o contador responsável por cada um dos escritórios do referido município. No decorrer da aplicação, os dados obtidos foram coletados e analisados com a finalidade de conhecer o perfil empreendedor desses profissionais. De acordo com a Delegacia do CRC do Piauí, a cidade de Picos possui 38 escritórios de contabilidade com registros ativos, nos quais todos estes foram submetidos a esse questionário. No entanto, apenas 18 retornaram com respostas, constituindo-se, por conseguinte, nos participantes desta pesquisa.

Quanto aos procedimentos metodológicos, a natureza do estudo é aplicada, o tipo de pesquisa é descritivoexploratório, e a abordagem é qualitativa e quantitativa. Segundo Marconi \& Lakatos (2007, p. 20), "[...] a pesquisa aplicada caracteriza-se por seu interesse prático, isto é, que os resultados sejam aplicados ou utilizados, imediatamente, na solução de problemas que ocorram na realidade".

De acordo com o objetivo do estudo traçado, a pesquisa é descritiva, pois analisou e descreveu o perfil dos profissionais de contabilidade, expondo as características de uma determinada população ou fenômeno, demandando técnicas padronizadas de coletas de dados (Prodanov \& Freitas, 2013).

A abordagem quantitativa requer o uso de recursos e técnicas de estatística, procurando traduzir em números os conhecimentos gerados pelo pesquisador. Prodanov \& Freitas afirmam que "enquanto, a abordagem qualitativa diz que o ambiente natural é fonte direta para coleta de dados, interpretação de fenômenos e atribuições de significados" (2013, p. 70).

Inicialmente, foi realizada pesquisa bibliográfica, embasada em livros físicos, digitais, artigos científicos de periódicos especializados, acessados, especialmente, por plataformas como o Google Acadêmico, Scielo e Periódicos CAPES, a partir de materiais já publicados (Prodanov \& Freitas, 2013).

Diante do contexto de pandemia, o questionário foi aplicado pelo Google Formulários, em virtude da facilidade no manuseio e na tabulação dos dados coletados. Os dados qualitativos coletados foram analisados através da análise de discurso.

A análise de discurso concebe a linguagem como mediação necessária entre o homem e a realidade natural e social. Essa mediação, que é o discurso, torna-se possível tanto a permanência e a continuidade quanto o deslocamento e a 
transformação do homem e da realidade em que ele vive. O trabalho simbólico do discurso está na base de produção da existência humana (Orlandi, 2009, p. 15).

Destaca-se ainda que o questionário possuía no total 16 perguntas, sendo essas objetivas e subjetivas. Das 13 objetivas, levou-se em consideração não só perguntas que mencionam as características empreendedoras, como também se destacou aspectos como: gênero, idade e nível de formação de cada participante. No que se refere às perguntas subjetivas, solicitou-se: e-mail, nome do contador responsável e nome do escritório. Ressalta-se que o projeto desta pesquisa foi aprovado pelo Comitê de Ética em Pesquisa, sob número CAAE 35912420.4.0000.5210.

\section{Conceituação do Empreendedorismo}

No Brasil, o empreendedorismo vem sendo difundido desde a década de 90, com a interferência do fenômeno da Globalização, quando houve uma maior abertura da Economia. Esse fenômeno fez com que as empresas de todos os portes e setores começassem a se modernizar para permanecer no mercado, trazendo, com isso, um aumento da competitividade, do desemprego e, ainda, dificuldades econômicas para o país (Dornelas, 2001).

Destaca-se ainda que a primeira fase do desenvolvimento da contabilidade no cenário brasileiro foi marcada pela intervenção da legislação no desenvolvimento dos procedimentos contábeis, como também pela influência da Escola Italiana no pensamento contábil dessa fase (Schmidt, 2000).

A relação entre empreendedorismo e contabilidade inicia-se a partir da utilização do serviço contábil por empreendedores. Apesar destes possuírem características que os diferem de outros profissionais como criatividade, determinação e iniciativa; por sua vez, não possuem capacidade para gerenciar seu negócio. A partir disso, acabam precisando da assessoria técnica contábil que é oferecida pelo contador. Sendo tal assessoria considerada o segundo serviço mais procurado por empreendedores, a contabilidade acaba servindo-lhes como uma fonte de apoio (Sabra et al., 2018).

Em face das mudanças contínuas no cenário econômico atual, a contabilidade, como uma ciência que estuda o patrimônio, vem ganhando força, tornando-se um suporte necessário no âmbito das organizações. Atualmente, para que se possa abrir um negócio, é de suma necessidade que se tenha auxílio de um contador, para que este possa ajudar no amadurecimento e no sucesso do empreendimento (Figuerôa et al., 2017).

Através das diferentes necessidades da sociedade, o mundo dos negócios tem sido cenário de várias possibilidades e iniciativas. Assim como este também tem apresentado características, como a alta competitividade, geração de inovação, desenvolvimento e empregos. Dessa forma, faz-se necessária a existência de profissionais dentro de uma organização que detenha características inovadoras e criativas, provenientes do fenômeno do empreendedorismo, com o intuito de crescimento e sucesso, que será almejado tanto para o profissional quanto para a própria empresa (Ribeiro et al., 2019).

Diante de uma era de transformação, o termo empreendedorismo encontra-se associado com a capacidade de se criar,

inovar, transformar algo que já existe de uma forma revolucionária nunca vista ou pensada. É por detrás dessas ações, capacidades e pensamentos, que irão surgir, ocasionalmente, indivíduos que irão se utilizar destas habilidades, fazendo com que esse processo possa acontecer, são os chamados empreendedores (Dornelas, 2001).

A maioria das definições sobre o fenômeno do empreendedorismo tem em comum uma concordância quanto à definição do termo: a capacidade para tomar iniciativa; a habilidade de organizar e reorganizar mecanismos sociais e econômicos, a fim de transformar recursos e situações para proveito prático, e a capacidade de aceitar o risco ou o fracasso (Fischer et al., 2008).

O instrumento específico dos empreendedores é a inovação. Através desta eles exploram a mudança como uma forma de oportunidade para um negócio diferente ou um serviço diferente, podendo, ainda, apresentá-la como uma disciplina capaz 
de ser apreendida e praticada. De forma deliberadamente proposital, os empreendedores ainda precisam buscar as fontes de inovação, por meio das mudanças e dos sintomas destas que possam servir de indicativos para que uma inovação seja considerada exitosa. Assim os empreendedores precisam conhecer e pôr em prática os princípios da inovação bem-sucedida (Drucker, 1987).

Existem várias correntes de pensamento que estudam esse fenômeno, não havendo uma definição consensual do termo empreendedor. A abordagem com enfoque econômico associa os empreendedores com as inovações, enquanto o comportamentalista concentra-se nas características do comportamento empreendedor, destacando ainda a capacidade e o dinamismo desse indivíduo como peças fundamentais para o sucesso do empreendimento e o desenvolvimento de um país (Fischer et al., 2008).

\section{Perfil Profissional do Contador}

O profissional contábil exerce uma função imprescindível de grande responsabilidade para a sociedade. A função assumida por este, suas prerrogativas profissionais e o conjunto de informações por ele gerenciadas, torna-o um dos principais agentes no processo de gestão das entidades. No entanto, faz-se necessário que esse profissional entenda claramente sua relevância e sua atividade na sociedade, só assim este poderá responder aos questionamentos que o cercam (Santos et al., 2011).

Destaca-se que, no ano de 1945, o curso de bacharelado em Ciências Contábeis foi instituído e reconhecido no Brasil, através do Decreto-Lei n ${ }^{\circ} 7.988$, sendo titulado como Curso de Ciências Contábeis e Atuariais. O curso possuía a duração de quatro anos, concedendo o título de bacharel aos seus concluintes. A grade curricular tinha como disciplinas: Contabilidade Geral, Organização e Contabilidade Industrial e Agrícola, Organização e Contabilidade Bancária, Organização e Contabilidade de Seguros, Contabilidade Pública e Revisões e Perícia Contábil (Peleias et al., 2007).

Até o ano de 1975, o ensino de Contabilidade no Estado do Piauí era praticado através de escolas de comércio e escolas técnicas. Em seguida, começou a funcionar o primeiro curso de Ciências Contábeis na Universidade Federal do Piauí. Passados alguns anos, o Ministério da Educação (MEC) veio a autorizar o funcionamento do curso de graduação em Ciências Contábeis nas instituições de ensino superior (Magalhães \& Andrade, 2004).

Em 1993 o Campus de Picos foi criado por meio da Lei Estadual n. 4.619. Já no dia 30/03/1994, através do Decreto Estadual n. ${ }^{\circ}$ 9.170, o Campus foi denominado "Campus Professor Barros Araújo", no qual, nesta mesma época, iniciou suas atividades com a implementação do curso de Ciências Contábeis (PPC, 2014).

As diretrizes curriculares nacionais que compõem a estrutura curricular do curso de bacharelado em Ciências Contábeis foram instituídas pelo Ministério da Educação (MEC), através da Resolução CNE/CES 10/2004. Essa resolução dispõe ainda que as Instituições de Ensino Superior (IES) devem estabelecer em seus projetos pedagógicos o perfil profissional que é almejado para os seus formandos na área, em termos de competências e habilidades (Tamer et al., 2013).

A estrutura curricular do curso de Ciências Contábeis da Universidade Estadual do Piauí (UESPI) reflete a preocupação desta instituição em relação à formação acadêmica do egresso com as características definidas em seu Projeto Pedagógico do Curso de Ciências Contábeis (PPC). Dessa forma, essa estrutura contempla os seguintes aspectos: flexibilidade, interdisciplinaridade, compatibilidade de carga horária e articulação da teoria com a prática. Já os conteúdos curriculares essenciais do Curso de Graduação em Ciências Contábeis da UESPI encontram-se alinhados às Diretrizes Curriculares Nacionais (DCN). Atualmente o curso possui 3.030 horas, integralizadas em 08 (oito) semestres letivo (PPC, 2014). Ressaltese que, apesar da citação aqui feita à UESPI, a pesquisa foi realizada nos âmbitos dos escritórios contábeis de Picos, tendo apenas a instituição como referência no que se refere ao aspecto da graduação.

Por intermédio da matriz curricular do curso de Ciências Contábeis, disponibilizada pela UESPI a partir do Projeto 
Pedagógico do Curso de Ciências Contábeis, do campus Professor Barros Araújo, os discentes possuem acesso às disciplinas ofertadas pelo curso e seus respectivos semestres. Dentre elas, dá-se ênfase à disciplina de Empreendedorismo, ofertada no sexto período, que prioriza a formação futura de um contador-empreendedor (PPC, 2014).

Uma formação que tenha um modelo com ênfase no empreendedorismo surge como uma interessante opção para os cursos, uma vez que possibilita a união entre o conhecimento teórico adquirido juntamente com a exploração de oportunidades de mercado, formando, dessa maneira, um profissional orientado para além da cultura do emprego (Chiavenato, 2007).

O Artigo $3^{\circ}$ da Resolução CNE/CES 10/2004 do Conselho Nacional de Educação estabelece que o curso de Ciências Contábeis deve proporcionar aos futuros profissionais de contabilidade diversas competências, dentre estas estão: a compreensão do profissional no que se refere às questões científicas, técnicas, sociais, econômicas e financeiras, dentro do âmbito nacional e internacional e nos diferentes modelos de organização; a apresentação de pleno domínio das responsabilidades funcionais que envolvem apurações, auditorias, perícias, arbitragens, noções de atividades atuariais e de quantificações de informações financeiras, patrimoniais e governamentais, com a plena utilização de inovações tecnológicas; como também, a capacidade crítico-analítica de avaliação, quanto às implicações organizacionais diante do advento da tecnologia da informação (Brasil, 2004).

Diante das competências e habilidades desejadas no currículo do profissional formado, destacam-se: demonstração de uma visão sistêmica e interdisciplinar da atividade contábil; aplicação adequada da legislação contábil; desenvolvimento, análise e implantação de sistemas de informação contábil e de controle gerencial, ética e prerrogativas que lhe são prescritas através da legislação específica, dentre outras. Assim, surgem responsabilidades e atividades que devem ser assumidas por um profissional que se encontra devidamente capacitado e comprometido (Leal et al., 2008).

De acordo com as atribuições profissionais do perfil do contador, verifica-se, no Decreto-Lei $n^{\circ}$ 9.295/46, que o trabalho técnico do contador se volta para a escrituração dos livros de contabilidade obrigatórios, bem como de todos aqueles necessários ao conjunto da organização contábil e levantamento dos respectivos balanços e demonstrações. Diante de todas essas atribuições, esse profissional ainda possui a função de fazer perícias judiciais ou extrajudiciais, revisar balanços de contas, dentre outras atribuições (Eckert et al., 2015).

Na contabilidade, o profissional deve possuir postura ética, por gerar informações que serão utilizadas para os fins de controle e decisão, incluindo ainda a avaliação do desempenho da entidade (Iudícibus, 2010).

Em 1946, foram implementados o Conselho Federal e os Conselhos Regionais de Contabilidade, através do DecretoLei n. ${ }^{\circ}$ 9.295. Estes assumem a função de fiscalizar e organizar a classe contábil. O mesmo decreto ainda foi capaz de assumir, como também definir, o perfil desses profissionais, limitando as atribuições dos contabilistas (Santos et al., 2011).

De acordo com o Conselho Federal de Contabilidade, a regulamentação da profissão ocorreu em 1946. Acredita-se que, com o passar dos anos, a contabilidade tornou-se essencial para a administração dos negócios, trazendo resultados satisfatórios. Isso é comprovado pela grande busca nas universidades pelo curso de Ciências Contábeis (Boniatti et al., 2014).

A Contabilidade é normatizada pela Lei 6.404/76, como também pelo Código Civil, que conferem poderes ao Banco Central para emissão das regras contábeis específicas às instituições financeiras, fazendo o mesmo em relação à Comissão de Valores Mobiliários (CVM), em termos de companhias abertas. (Martins et al., 2007).

A valorização da profissão contábil ocorreu recentemente, e encontra-se relacionada às interferências do fenômeno da globalização e na busca de convergência por padrões internacionais de contabilidade. No entanto, diante dessa colocação, o contador, que antes era visto apenas como um "guardador de livros" ou apenas aquele que calcula impostos, hoje faz parte da equipe de tomada de decisões, dentro do processo de gestão de uma empresa (Marin et al., 2014). 


\section{Empreendedorismo na Valorização do Profissional Contábil}

Na sociedade contemporânea, as constantes mudanças socioeconômicas têm levado as organizações a buscar novas formas de estruturação, visando o alcance de melhores níveis de competitividade. Diante da complexidade e da incerteza do ambiente em que as mudanças estão inseridas, estas exigem das organizações a criação de capacidades dinâmicas de novas práticas de gestão e a busca cada vez mais constante por profissionais qualificados (Leal et al.,2008).

Em decorrência das diferentes demandas da sociedade, o mundo dos negócios tem sido cenário de várias possibilidades e iniciativas, como também tem apresentado características como a alta competitividade, geração de inovação, desenvolvimento e empregos. Dessa forma, faz-se necessário a existência de profissionais dentro de uma organização que detenha características inovadoras e criativas, provenientes do fenômeno do empreendedorismo, com o intuito de crescimento e sucesso, que será almejado tanto para o profissional quanto para a própria empresa (Ribeiro et al., 2019).

A valorização da profissão contábil ocorreu recentemente e encontra-se relacionada às interferências do fenômeno da Globalização que, por sua vez, solicitam a busca de convergência com padrões internacionais de contabilidade. No entanto, diante dessa colocação, o contador, que antes era visto apenas como um "guardador de livros" ou apenas aquele que calculava impostos, hoje é um profissional que passa a desempenhar um papel importante, fazendo parte da equipe de tomada de decisões, dentro do processo de gestão de uma empresa (Marin et al., 2014).

A Globalização de certa forma modificou a atuação desse profissional, uma vez que, diante dessa nova realidade, este não deve apenas se dedicar exclusivamente à sua profissão, tendo ainda que estar sempre em busca de outras áreas de conhecimento; ou seja, deve voltar-se para o perfil de um profissional que se encontra sempre aberto para a procura de conhecimento em todas as áreas de informação. Outrossim, o campo de atuação contábil está cada vez mais ampliado oferecendo oportunidades de emprego e de realização profissional, mostrando também que a contabilidade se tornou importante à medida que ocorre desenvolvimento econômico (Souza et al., 2016).

Diante dessa nova realidade, percebe-se que, para que os contadores possam efetivamente contribuir no processo de geração de valor às organizações, estes devem absorver novas habilidades pessoais, desenvolvendo, dessa maneira, a capacidade de entendimento do negócio, adotando assim uma postura mais empreendedora. Enfim, estes profissionais devem absorver requisitos que os credenciem a desenvolver uma maior inserção no processo de gestão (Cardoso et al., 2006).

De acordo com o Conselho Federal de Contabilidade, em sua resolução no 560/83, o profissional contábil, dentro dos vastos tipos de profissionais, pode exercer vários tipos de atividades; podendo ser considerado ainda como: empregado, profissional liberal, autônomo ou empresário (Ribeiro et al., 2019).

Sobre as características que definem um profissional contábil como empreendedor afirma-se que:

Pode-se dizer que um profissional contábil apresenta características empreendedoras se ele for além do usual, e buscar novas ferramentas que indiquem sua diferenciação e que o destaquem entre os demais na sua área de atuação. Essa diferenciação estará ligada à utilização de artefatos gerenciais (Anjos et al., 2011, p. 20).

Os profissionais da contabilidade destacam-se como grandes incentivadores do empreendedorismo, devido a sua capacidade de estimular os empresários, com os quais trabalham e possuem uma relação de confiança, os melhores comportamentos empreendedores (Matias et al., 2013).

Nesse sentido, diante do cenário das empresas, percebe-se que os contadores possuem uma posição estratégica dentro destas no que se refere ao estímulo, ao desenvolvimento empreendedor e, consequentemente, ao desenvolvimento econômico do país. As funções desenvolvidas por estes estão relacionadas com o planejamento, o acompanhamento da execução e os controles financeiros e operacionais nas empresas (Athayde \& Martins, 2010).

Faz-se necessário que, em qualquer profissão, o indivíduo inclua no seu perfil profissional atitudes que permeiam o 
trabalho de um indivíduo empreendedor. Destaca-se, aqui, no caso, a figura do contador que não deve se limitar, em exclusivo, ao simples desenvolvimento de suas funções. Ele deve estar sempre preparado para a participação no processo de tomada de decisão, visando sempre identificar e retificar as dificuldades e adversidades que surgem ao longo do percurso, por meio de ações empreendedoras, baseando-se nas informações geradas pela contabilidade. Nesse sentido, pode-se dizer que o profissional contábil é importante no desenvolvimento e na constituição de um empreendimento, por ser capaz de captar o conhecimento que precisa para a composição do seu próprio negócio e de adicionar este conhecimento como informações que suscitam confiança e credibilidade aos seus usuários (Santos et al., 2015).

O empreendedor contábil, na busca do sucesso profissional, precisa desenvolver uma imagem positiva, tornando-a uma marca pessoal; ou seja, esse profissional precisa elaborar e, ao mesmo tempo, oferecer produtos e serviços inovadores, identificando e entendendo as necessidades dos clientes, ao mesmo tempo que se atualiza com as tendências e perspectivas do mercado em que o seu cliente atua (Peleias et al., 2007).

\section{Resultados e Discussões}

Esta seção possui os dados referentes à aplicação da pesquisa proposta com o intuito de se conhecer o perfil profissional dos contadores e contadoras, destacando-se, dessa maneira, o cenário da cidade de Picos, Piauí. Para a aplicação da pesquisa, consultou-se a Delegacia do CRC (Conselho Regional de Contabilidade) de Picos - PI, para se ter como base a quantidade de escritórios que a cidade possui, como também para se obter possíveis informações para contato. Mediante a quantidade de escritórios contábeis, foi planejado o material utilizado para a aplicação da parte prática do estudo que foi feito a partir da utilização de um questionário. Diante do contexto de pandemia, a aplicação desse questionário foi feita através do Google formulários, por conta da facilidade no manuseio e na tabulação dos dados coletados. Enviou-se para os participantes o link do questionário feito a partir da plataforma do Google formulários por meio de mensagens criptografadas pelo aplicativo WhatsApp, como também uma cópia do Termo de Consentimento Livre e Esclarecido (TCLE). O CRC de Picos, através de uma de suas colaboradoras, via mensagem por e-mail, forneceu a informação de que a cidade possuía 38 (trinta e oito) escritórios de Contabilidade, porém apenas 18 (dezoito) desses escritórios retornaram com respostas ao questionário.

O questionário estruturado e fechado foi enviado via e-mail para o contador responsável por cada escritório. No decorrer da aplicação, os dados obtidos foram coletados e analisados com a finalidade de conhecer o perfil empreendedor desses profissionais. Mediante isso, os dados foram tabulados e, em seguida, confeccionaram-se tabelas para uma melhor visualização. Diante disso, também foi feita uma exposição do total de respostas dadas pelos participantes que faziam referência às perguntas que tinham como resposta ou sim, ou não, dentro do questionário aplicado.

No que se refere à pergunta quanto ao gênero, temos as seguintes informações tabuladas a seguir:

Tabela 1 - Desenvolvimento da atividade empreendedora quanto ao gênero.

\begin{tabular}{cc}
\hline GÊNERO & TOTAL \\
\hline MASCULINO & 12 \\
\hline FEMININO & 6 \\
\hline
\end{tabular}

Fonte: Dados da pesquisa elaborado pelos autores.

Em relação à próxima pergunta do questionário, relacionada à idade, obtiveram-se as informações tabuladas a seguir: 
Tabela 2 - Desenvolvimento da atividade empreendedora quanto à faixa etária.

\begin{tabular}{cc}
\hline FAIXA ETÁRIA & TOTAL \\
\hline Entre 18 a 25 anos & 3 \\
\hline Entre 26 a 35 anos & 8 \\
\hline Entre 36 a 45 anos & 1 \\
\hline Entre 46 a 55 anos & 5 \\
\hline Acima de 56 anos & 1 \\
\hline
\end{tabular}

Fonte: Dados da pesquisa elaborados pelos autores.

Aqui utilizaram-se os dados tabulados pela Global Entrepreneurship Research Association (GERA) (2016) para a análise das taxas que medem a atividade empreendedora nos países, como também as faixas etárias como pré-requisito para a avaliação. No Brasil, por exemplo, as taxas específicas de empreendedores estabelecidos (TEE), segundo os dados apontados pelo GERA, apresentam uma grande variação de um extremo que vai de um valor mínimo com uma TEE de 5,5\% para indivíduos entre 18 a 24 anos de idade e um valor máximo de 24,2\% para respondentes com idades entre 45 a 54 anos. Enquanto a faixa etária de 25 a 34 variou com 11,7\%; seguido dos respondentes com 35 a 44 anos de idade representando 22,4\%; e por fim 55 a 64 anos com 23,9\% (Monitor, 2016).

Diante do que foi estabelecido anteriormente, pode-se confirmar que, mediante os dados apresentados no Brasil, a cada 100 pessoas com idade entre 45 e 54 anos, 24 são responsáveis por empreendimento com mais de 42 meses de funcionamento. Em suma, de uma forma geral, no país, a TEE ficou mais baixa para os indivíduos mais novos e mais alto (acima de 20\%) para os indivíduos com mais de 35 anos (Monitor, 2016).

De acordo com as taxas de empreendimentos estabelecidos, fornecidas pela TEE, e segundo os dados coletados dentro desta pesquisa, diante da aplicação do questionário nos escritórios de contabilidade, nota-se uma dominância de contadores na faixa etária de 26 a 35 anos, seguido de contadores com uma faixa etária de 46 a 55 anos, possuindo ainda uma porcentagem mínima de contadores empreendedores na faixa etária de 18 a 25 anos.

Confirma-se, dessa maneira, que a atividade empreendedora estabelecida, diante do que foi exposto pela Global Entrepreneurship Research Association (2016) e dos dados apresentados na pesquisa, traz uma pequena significância no que se refere aos novos contadores. Porém, à medida que a experiência profissional e a idade aumentam, apresenta-se uma relação positiva entre idade do empreendedor e a permanência do seu empreendimento.

Voltando-se para a próxima pergunta do questionário, perguntou-se se os participantes conheciam o termo empreendedorismo. Como resposta, obteve-se que todos os 18 contadores conheciam o termo e o adotavam como postura em sua gestão.

Quando perguntados se eles, como contadores, julgavam que existia uma relação entre esses dois campos de estudo, quais sejam, Empreendedorismo e Contabilidade, a resposta dada por todos foi "sim". O Empreendedorismo auxilia no processo de formação, de inovação do profissional da área contábil, apresentando-se como uma forma de se reinventar, se valorizar e continuar no mercado de trabalho. Isso possibilita a mediação dos fatores de riscos e aprimora a capacidade de tomada de decisão, elevando também a capacidade de percepção e visão do futuro.

Tendo como base o ambiente dos negócios e como este vem evoluindo rápido, considerando-se a utilização das novas tecnologias e a constante ruptura com paradigmas, percebe-se que, quanto ao nascimento e ao crescimento de um ambiente empreendedor, há a necessidade de investimentos iniciais e de permanente geração de lucros, tanto para sócios, quanto para proprietários, bem como a geração de emprego, renda e movimentação econômica (Assis \& Costa, 2016).

Diante desse cenário de evolução, a estratégia empresarial sofre a interferência de inúmeros desafios como, por 
exemplo, as frequentes mudanças que ocorrem no ambiente de negócios. Portanto, para enfrentá-los e ainda prosperar, torna-se necessário que gestores e proprietários comportem atributos que possam destacá-los frente à concorrência (Lizote \& Verdinelli, 2014).

A globalização e a mudança desses cenários socioeconômicos despertam para uma ação efetiva no intuito de inovação, superação e agregação de valores. Percebe-se dessa maneira que a própria situação requer mudanças que serão benéficas para a manutenção desses empreendimentos, visando sempre a questão do futuro e a questão econômica.

Os problemas complexos que irão surgir nos ambientes de negócios exigem que as equipes de trabalho apresentem características apropriadas para enfrentá-los, fazendo-se com que, desta forma, a ênfase se direcione para as pessoas, seus comportamentos e seus modos de trabalho. As organizações nesse âmbito precisam contar com trabalhadores comprometidos, capazes de perceber e captar oportunidades; ou seja, que tenham ou estejam dispostos a desenvolver suas competências. Os contadores, por exemplo, ocupam uma posição estratégica para as empresas, no estímulo ao desenvolvimento empreendedor e consequente desenvolvimento econômico do país. Suas atividades estão relacionadas com planejamento, acompanhamento da execução e controles financeiros e operacionais; características estas existentes em diversos empreendedores (Lizote \& Verdinelli, 2014).

Pode-se destacar ainda que a introdução do ensino do Empreendedorismo no curso de graduação em Ciências Contábeis vem assumindo um caráter de dupla dimensão. Por um lado, as bases desse estudo, adequadamente planejadas, servem para definir uma metodologia abrangente, envolvendo não só os aspectos técnicos como também atitudinais do futuro profissional contábil. Por outro lado, incutem no aluno desta graduação a importância de desenvolver o Empreendedorismo não só para si, como também para o desenvolvimento de outros empreendedores, sinalizando, por sua vez, o quanto essa mudança de mentalidade irá resultar no amadurecimento profissional do contador e no desenvolvimento da sociedade no qual atua e participa (Matias et al., 2013).

Pode-se destacar, assim, que a relação entre a contabilidade e o empreendedorismo se estabelece desde o momento em que o profissional contador tem o contato com o estudo do empreendedorismo, ainda dentro da graduação. Tal relação e tal contato destacam a importância desse estudo na formação do contador e na reflexão quanto a sua postura profissional e quanto a sua valorização dentro do mercado.

O profissional contábil possui uma posição significativa e estratégica em relação a possuir tanto a capacidade de estimular a atividade empreendedora quanto a condição de possuir as características que se assemelham àquelas definidas para um bom empreendedor.

Confirma-se dessa maneira que os 18 escritórios possuem gestão empreendedora e que estes terão a capacidade de desenvolver características que irão ajudá-los a se manter e a prosperar dentro do mercado de trabalho cada vez mais competitivo e inovador.

Entende-se que atualmente as entidades devem adotar uma gestão empreendedora para que possam prosperar e, ao mesmo tempo, sobreviver mediante um contexto de grandes mudanças. É preciso também promover a liberdade de ação em todos os níveis da empresa de modo participativo; o que deve ser a regra de conduta e orientação gerencial no processo da tomada de decisões (Lizote \& Verdinelli, 2014).

Ainda dentro do questionário, perguntou-se aos contadores se eles gostavam do que faziam. Diante dessa indagação, todos responderam que "sim". Este traço está presente na constituição de um empreendedor.

Dentre as características de um empreendedor, temos a característica de serem considerados otimistas e apaixonados pelo que fazem. Os empreendedores adoram o trabalho que realizam, sendo esse amor pelo que fazem um de seus maiores combustíveis para continuar fazendo o que desenvolvem. Eles são animados e autodeterminados. Dessa forma tornam-se os melhores vendedores de seus produtos e serviços, pois sabem melhor do que qualquer outra pessoa como o fazer (Dornelas, 
2001).

O empreendedor é visto como um indivíduo que quase nunca se desvia dos seus objetivos. Se possível, ele age repetidamente e é capaz de modificar a sua estratégia sempre que encontra condições ou necessite, no intuito de enfrentar desafios e superar obstáculos, mesmo que, diante da situação, seja necessário o sacrifício pessoal (Carreira et al., 2015).

Dessa forma, pode-se destacar que o profissional contábil da cidade de Picos possui característica empreendedora, considerando-se que esses indivíduos gostam da profissão na qual atuam, mostrando-se motivados e determinados, ainda que as circunstâncias exijam sacrifícios.

Já quando perguntado se possuíam iniciativa para empreender um novo negócio, obteve-se as seguintes respostas: 15 responderam que sim, possuem essa iniciativa e 3 responderam que não, não possuem iniciativa.

Os empreendedores são considerados independentes e constroem o seu próprio destino, estão sempre à frente das mudanças. Independentes, querem empreender em algo novo, determinar seus próprios passos, serem seus próprios patrões e gerar empregos (Dornelas, 2001).

Destaca-se ainda o empreendedor revolucionário, que é considerado aquele que se estabelece no mercado através da criação de algo único. Ressalte-se ainda que aquilo que pode tornar seu negócio bem-sucedido encontra-se na junção de duas coisas: o negócio oportuno e apropriado e o espírito empreendedor bem-dotado (Chiavenato, 2007).

Conclui-se dessa maneira que a maioria dos contadores possui habilidade empreendedora no aspecto de se encontrarem dispostos para a criação de algo novo.

Voltando-se para o questionário, quando perguntado aos contadores se eles sabiam utilizar os recursos que possuem para melhorar de forma criativa o ambiente social e a interação de seus colaboradores, todos responderam que sim, que sabiam utilizar esses recursos de forma positiva.

Considerados determinados e dinâmicos, os empreendedores conseguem implantar suas ações com muito comprometimento, passando por cima das adversidades e dos obstáculos, fazendo acontecer (Dornelas, 2001).

Dessa forma, percebe-se que o contador possui capacidade de comprometimento de suas ações mediante o seu ambiente de trabalho e de interação com os seus funcionários.

Quando perguntados sobre a capacidade de aceitar e assumir os riscos e a possibilidade de fracassar, 17 responderam que sim e apenas 1 disse que não.

Antes de iniciar seu próprio negócio, o empreendedor já assume vários riscos, dentre esses se destacam: riscos financeiros, que são decorrentes dos investimentos do seu próprio capital e do abandono do seu emprego seguro ou até mesmo de uma carreira; riscos familiares, ao envolver a família no negócio; riscos psicológicos, pela possibilidade de fracassar em negócios arriscados (Chiavenato, 2007).

Empreendedores possuem a capacidade de correr riscos calculados, sabendo gerenciar o risco e avaliando ainda as reais chances do sucesso profissional. Os riscos ainda estão associados aos desafios e, quanto maior o desafio, mais estimulante será a sua jornada empreendedora (Dornelas, 2001).

Os contadores analisados possuem também capacidade de assumir riscos mediante as condições enfrentadas dentro do mercado de trabalho.

Quando perguntados se consideravam a si próprios como pessoas criativas, capazes de se reinventar, lançar algo que está no papel, transformando isso em algo concreto, diante das respostas dadas, 13 responderam que sim, enquanto 5 responderam que não.

Em relação a este questionamento, vê-se que o empreendedor, por possuir criatividade e um alto nível de energia, demonstra ainda possuir imaginação e perseverança. Tais aspectos, se unidos adequadamente, habilitam este individuo a transformar uma simples e mal estruturada ideia em algo concreto e bem-sucedido dentro do mercado (Chiavenato, 2007). 
Sendo assim, a maioria dos contadores estudados possui capacidade para se reinventar, transformar e criar, sendo que isso é considerada uma das principais características de um profissional empreendedor.

Voltando-se novamente para o questionário, quando perguntado se esses contadores possuíam capacidade de liderança, conseguindo dessa forma o respeito e a admiração de seus funcionários, sabendo, e antemão, que necessita de uma equipe competente para chegar ao sucesso, 16 responderam que sim, e apenas 2 responderam que não.

Sendo considerados ainda líderes e formadores de equipes, os empreendedores são respeitados e adorados por seus funcionários, pois os valorizam, estimulam e recompensam-nos, formando dessa maneira um time. Sabe-se ainda que a única maneira para se obter êxito e sucesso está na condição de possuir uma equipe de profissionais competentes, recrutando ainda as melhores cabeças para assessorá-los nos campos onde não possuem conhecimento (Dornelas, 2001).

Diante do que foi explanado na afirmação anterior, percebe-se que a capacidade de liderança, a formação de um time e o respeito por seus funcionários garantem o empreendedorismo. Com isso, percebe-se que a mútua colaboração exerce um papel de grande importância para o sucesso, como também a capacidade de liderar caracteriza-se como uma característica empreendedora marcante no processo de sobrevivência e manutenção do empreendimento.

Quando perguntados se os contadores conseguiam pensar a longo prazo, planejando cada passo do seu negócio desde o plano de negócio, a apresentação do plano a investidores, definição das estratégias de marketing e etc., tendo a visão de todas as atividades que irão se desenvolver, dentre as respostas obtemos que 16 responderam que sim, enquanto 2 responderam que não.

Dentre as características que definem um empreendedor, destaca-se a capacidade de planejar cada passo de seu negócio, desde o primeiro rascunho do plano de negócios, até a apresentação do plano para os investidores, definindo ainda as estratégias de marketing do negócio, tendo como base a visão do negócio que possui (Dornelas, 2001).

O marketing é visto por Cobra (2011, p. 373), como "o estudo e a preparação de todos os meios necessários para permitir à empresa aproximar, permanentemente e no interesse comum, as necessidades e os desejos do consumidor às possibilidades de produção".

Diante dessa afirmação ressalte-se ainda que o mercado de trabalho é capaz de recompensar o empreendedor que tem visão estratégica. Este, por ser considerado um criador de soluções e inovações, possui ainda zelo quanto ao atendimento ao cliente e sabe gerir o negócio com profissionalismo e seriedade (Chiavenato, 2007).

Dessa forma, conclui-se que a maioria dos contadores estudados possui essa capacidade de pensar a longo prazo, organizando todas as etapas de seu empreendimento, desde a sua constituição. Essa característica os diferencia dos demais profissionais no intuito de ser bem-vista dentro do mercado de trabalho.

Quando perguntados se possuíam conhecimento sobre o seu próprio negócio, todos responderam que sim.

Os empreendedores possuem um desejo excessivo pelo saber, aprendem continuamente, pois sabem que a única forma de se obter o êxito em seu empreendimento é ter um domínio sobre um ramo de negócio (Dornelas, 2001).

Para finalizar o questionário, perguntou-se se os contadores estão sempre em busca de qualificação e inovação, ao passo que todos responderam que sim.

Pode-se, dessa forma, afirmar que o avanço da economia está atrelado à criação dos pequenos negócios, em virtude da geração de empregos, das inovações, do pagamento de impostos e da riqueza das nações (Chiavenato, 2007).

A evolução do comportamento empreendedor tem sido colocada na frente das agendas e debates políticos, econômicos e científicos, em vários países do mundo, destacando dessa maneira até mesmo o Brasil. Devido ter sido comprovada a influência dessa evolução sobre os setores econômico e social de uma nação. (Krüger \& Ramos, 2020).

Em suma, o profissional contábil da cidade de Picos- PI possui perfil empreendedor, na medida em que desenvolve as características de um empreendedor, desde a implementação, desenvolvimento de seus trabalhos, como também na 
manutenção de seus empreendimentos. Esse profissional possui ainda uma posição significativa e estratégica em relação a possuir tanto a capacidade de estimular a atividade empreendedora quanto à constatação de que possui características que se assemelham às definidas para um empreendedor.

\section{Considerações Finais}

O empreendedorismo é compreendido como uma forma de inovar, criar e/ou agregar valor ao que já existe de uma forma diferente, desenvolvendo dessa maneira uma fonte de geração de renda; ou, ainda, como a capacidade de gerar impactos positivos sobre a economia. O termo "empreender" vem ocupando um espaço significativo não só na esfera econômica como também histórica e acadêmica, visto que, dentro da literatura, muitos autores trazem um apanhado científico do termo desde a origem, quanto a suas atribuições e qualificações.

Os indivíduos que decidem empreender são denominados de empreendedores, estes possuem características e atribuições que vão desde a capacidade de inovar, criar, ser visionários, correr riscos calculados, dentre outros. Sempre em busca do mesmo objetivo conseguir melhores condições de vida, geração de emprego e renda.

A Contabilidade, vista como uma ciência que estuda o patrimônio, é de suma importância para os empreendedores que necessitam de sua consultoria, desde a constituição do empreendimento até o início das atividades deste. Desta feita, existe um elo forte entre Contabilidade e Empreendedorismo. Dentro da matriz curricular do curso de Contabilidade o aluno paga a disciplina de Empreendedorismo e percebe-se que a maioria desses alunos, quando saem da faculdade, saem com a visão de criar o seu próprio negócio, criando seus próprios escritórios contábeis.

Dentro de um mercado de trabalho cada vez mais competitivo, cheio de inovações faz-se necessário que o profissional contábil esteja cada vez mais preparado. Nesse cenário, é preciso saber inovar e agregar características e habilidades de um profissional empreendedor para que se possa manter dentro do mercado. Ademais, não só o mercado passa por transformações, mas a própria contabilidade passa por transformações constantes e que precisam ser incorporadas dentro dos escritórios contábeis.

Diante dos artigos científicos encontrados dentro da literatura, pode-se perceber a relação tênue entre Empreendedorismo e Contabilidade. Em função disso, destaca-se a importância do Empreendedorismo na atuação e na valorização da profissão contábil como uma forma de esse profissional sobreviver dentro de um mercado cada vez mais globalizado e cheio de inovações. Sabendo-se ainda que este profissional necessita acompanhar essas evoluções e estar sempre de prontidão para desenvolver suas atividades.

Este artigo foi pensando e desenvolvido com o ideal de agregar valor, pensando não apenas no futuro da profissão contábil, como também em servir de base para a realização de outros estudos voltados para não somente para a área da contabilidade como também do empreendedorismo, transformando-se, assim, o pensamento desses profissionais quanto a sua atuação dentro do mercado de trabalho.

Em suma, mediante a aplicação e análise dos dados, percebeu-se ainda que os contabilistas aplicam características empreendedoras, desde a implementação, desenvolvimento de seus trabalhos, como também na manutenção de seus negócios. O profissional contábil possui ainda uma posição significativa e estratégica em relação a possuir tanto a capacidade de estimular a atividade empreendedora quanto a de constituir características semelhantes a de um empreendedor.

\section{Referências}

Andrade, F (2012). O contador pode ser um empreendedor? Café com ADM, São Luís, 27 dez. 2020, Administradores, s/p.

Anjos, L. C. M., Santos, P. D. C. F., Miranda, L. C., Silva, D. J. C., \& Santana, F. R. (2011). Conhecer e empreender: um estudo sobre a utilização de artefatos gerenciais em organizações contábeis. Navus-Revista de Gestão e Tecnologia, 1(1), 17-33. 
Assis, W. M. B., \& Costa, R. A. T. (2016). A gestão contábil financeira nas micro e pequenas empresas. Revista de Empreendedorismo e Gestão de Micro e Pequenas Empresas, 1(04), 143-155.

Athayde, M., \& Martins, G. D. A. (2010). O legado de Mcclelland e a educação empreendedora em contabilidade. In IV Congresso Anpcont.

Boniatti, A. O., Velho, A. D., Pereira, A., Pereira, B. B., \& Oliveira, S. D. (2014). A evolução da mulher no mercado contábil. Revista Gedecon-Gestão e Desenvolvimento em Contexto, 2(1), 19-27.

Brasil (2004). Resolução CNE/CES 10/2004. Dispõe sobre os cursos de graduação em ciências contábeis. http://portal.mec.gov.br/cne/arquivos/pdf/rces10_04.pdf.

Cardoso, J. L., Souza, M. A., \& Almeida, L. B. (2006). Perfil do contador na atualidade: um estudo exploratório. Revista Base (Administração e Contabilidade) da UNISINOS, 3(3), 275-284.

Carreira, S. S., Franzoni, A. B., Esper, A. J. F., Pacheco, D. C., Gramkow, F. B., \& Carreira, M. F. (2015). Empreendedorismo feminino: um estudo fenomenológico. NAVUS-Revista de Gestão e Tecnologia, 5(2), 6-13.

Cavalcanti, S. C. N., Moreira, M. A., \& Silva, P. B. (2018). O Empreendedorismo no Seio das Ciências Contábeis: Análise da Discussão Sobre Empreendedorismo no Congresso USP de Contabilidade. RIC, 12(3), 1.

Chiavenato, I. (2007). Empreendedorismo: dando asas ao espírito empreendedor. Editora Manole.

Cobra, M. (2011). Administração de marketing. (2a ed.), Atlas.

Dornelas, J. C. A. (2001). Empreendedorismo: transformando ideias em negócios. Campus.

Drucker, P. F (1987). Inovação e espírito empreendedor. Pioneira.

Eckert, A., Vanin, F., Mecca, M. S., \& Biasio, R. (2015). Utilizando a assessoria do escritório contábil gerencial em micro e pequenas empresas: a percepção dos gestores. Revista de administração e Negócios da Amazônia, 7(1), 126-142.

Fialho, F. A. P., Montibeller Filho, G., Macedo, M., Mitidieri, T. C (2007). Empreendedorismo na era do conhecimento. Visual Books.

Figueirôa, D. S. V. de; Lemos, Z. Z.; Leite, E (2017). O perfil empreendedor do contador no município de Custódia-PE, Revista Raites, Pernambuco, 3 (5), $10-36$

Fischer, A.; Nodari, T. M. dos S.; Feger, J. E (2008). Empreendedorismo: algumas reflexões quanto às características. Race, Unoesc, 7 (1), $39-52$.

Iudícibus, S (2010). Contabilidade introdutória. Atlas.

Leal, E. A., Soares, M. A., \& de Sousa, E. G. (2008). Perspectivas dos formandos do curso de Ciências Contábeis e as exigências do mercado de trabalho. Revista Contemporânea de Contabilidade, 5(10), 147-159.

Lizote, S. A., \& Verdinelli, M. A. (2014). Relação entre competências empreendedoras e desempenho: um estudo em empresas prestadoras de serviços contábeis. Revista de Contabilidade e Organizações, 8(22), 49-59.

Lucia, C. S (2012). Os desafios do empreendedor contábil. A contabilidade funciona bem na administração? Café com ADM, São Luís, 27 dez. 2020 , Administradores, $\mathrm{s} / \mathrm{p}$

Magalhães, F. A. C., \& Andrade, J. X. (2004). A Educação Contábil no Estado do Piauí diante da proposta de convergência internacional do Currículo de Contabilidade concebida pela ONU/UNCTAD/ISAR. In Congresso USP de Controladoria e Contabilidade (Vol. 6, pp. 1-15).

Marconi, M. D. A., \& Lakatos, E. M. (2007). Técnicas de pesquisa. (6a ed.), Atlas.

Marin, T. I. S., de Lima, S. J., \& Nova, S. P. D. C. C. (2014). Formação do Contador-o que o Mercado quer, é o que ele tem? Um Estudo sobre o Perfil Profissional dos Alunos de Ciências Contábeis da FEA-USP. Contabilidade Vista \& Revista, 25(2), 59-83.

Marion, J. C (2009). Contabilidade empresarial. (15a ed.), Atlas.

Martins, E., Martins, V. A., \& Martins, É. A. (2007). Normatização contábil: ensaio sobre sua evolução e o papel do CPC. Revista de Informação Contábil, $1(1)$.

Matias, M. A., Colares, A. C. V., Rocha, P. M., \& JUNIOR, L. E. D. C. (2013). O ensino de empreendedorismo nos cursos de graduação em ciências contábeis. Revista Catarinense da Ciência Contábil, 12(35), 63-78.

Monitor, G. G. E. (2016). 2016, GEM Global Entrepreneurship Monitor.

Orlandi, E. P (2009). Análise de discurso: princípios e procedimentos. Pontes.

Peleias, I. R., Silva, G. P. D., Segreti, J. B., \& Chirotto, A. R. (2007). Evolução do ensino da contabilidade no Brasil: uma análise histórica. Revista Contabilidade \& Finanças, 18(SPE), 19-32.

PPC (2014). Projeto pedagógico do curso de ciências contábeis. Campus Prof. Barros Araújo.

Prodanov, C. C; Freitas, E. C (2013). Metodologia do trabalho científico: método e técnicas da pesquisa e do trabalho acadêmico. Contexto. 
Research, Society and Development, v. 10, n. 9, e30510917953, 2021

(CC BY 4.0) | ISSN 2525-3409 | DOI: http://dx.doi.org/10.33448/rsd-v10i9.17953

Krüger, C., \& Ramos, L. F. (2020). Comportamento empreendedor, a partir de características comportamentais e da intenção empreendedora. Revista de Empreendedorismo e Gestão Pequenas Empresas, 9(4), 528-555.

Ribeiro, M. C., da Cruz, W. S., Procópio, J. G., \& Soares, M. C. (2019). Características Empreendedoras dos Profissionais de Contabilidade de Um Município da Amazônia Paraense. Revista Paraense de Contabilidade, 4(3), 64-77.

Sabra, M. A. R., Alves, A. T., Negreiros, M. C. V (2018). Contabilidade e empreendedorismo: de que forma empreendedorismo pode ajudar na valorização profissional do contador? Empreendedorismo, Gestão e Negócios, Amazonas, 7(7), 503-512.

Santos, D. F., de Souza Sobral, F., Correa, M. D., Antonovz, T., \& dos Santos, R. F. (2011). Perfil do profissional contábil: estudo comparativo entre as exigências do mercado de trabalho e a formação oferecida pelas instituições de ensino superior de Curitiba. Revista Contemporânea de Contabilidade, 8(16), $137-152$.

Santos, L. C., Moreira, G., \& Pires, J. G (2015). Perfil empreendedor dos contadores cadastrados na Associação de Contadores de Unaí/MG. FACTU, 12.

Schmidt, P (2000). História do pensamento contábil. Bookman.

Schumpeter, J. A (1982). Teoria do Desenvolvimento Econômico: uma investigação sobre lucros, capital, crédito, juro e o ciclo econômico. São Paulo: Abril Cultural.

Souza, A. P., Silva, A. M. L., Moraes, R. R., \& Santos, L. D. S. S. (2016). Empreendedorismo e oportunidade de novos negócios para os contadores do estado do Pará. Revista de Administração e Contabilidade-RAC, 3(5).

Tamer, C., Viana, C., Soares, L. A., \& Lima, M. (2013). Perfil do profissional contábil demandado pelo mercado de trabalho: um estudo no norte do Brasil. Revista Universo Contábil, 9(3), 143-162. 